\title{
PROTEÇÃO MULTINÍVEL DOS DIREITOS HUMANOS: LÓGICA MONISTA OU DUALISTA DO DIREITO?
}

\author{
HUMAN RIGHTS MULTILEVEL PROTECTION: \\ MONIST OR DUALIST LOGIC OF THE LAW?
}

Paula Regina Arruda de Azevedo

Paulo Máximo de Castro Cabacinha

\section{RESUMO}

0 presente artigo tem por fim analisar a possibilidade de embasamento uma teoria de proteção multinível dos direitos humanos tanto sob através de uma posição dualista quanto em uma posição monista do Direito. Partiu-se da contextualização da realidade em que coexistem fontes de proteção dos direitos humanos vigentes em um único Estado e a explicação do que vem a ser a teoria de proteção multinível dos direitos. Após reconstruiu-se os principais argumentos das teorias dualista/pluralista e monistas (nacionalista, internacionalista e moderado) do Direito, para, ao final, apontar a teoria que melhor se adequa à proteção dos direitos humanos.

Palavras-chaves: Direitos Humanos. Proteção Multinível dos Direitos Humanos. Monismo jurídico. Dualismo jurídico.

\section{ABSTRACT}

The purpose of this article is to examine if it would be possible to base a theory of multilevel protection of human rights under both a dualist and a monist position of the Law. It started from the contextualization of the reality 
that coexist sources of protection of human rights in a single State and the explanation of what comes to be the theory of multilevel protection of these rights. Afterwards, the main arguments of the dualist/pluralist and monist (nationalist, internationalist and moderate) theories of Law were reconstructed. In the end was chouse the theory that best suits the protection of human rights.

Keywords: Human Rights. Multilevel protections of Human Rights. Monism. Dualism.

\section{INTRODUÇÃo}

O presente artigo busca analisar a possibilidade de existência de uma teoria de proteção multinível dos direitos humanos tanto em um enfoque dualista quanto em um enfoque monista do Direito. Paratanto, através da revisão doutrinária, busca-se explanar as principais posições monistas e dualistas do Direito para, ao final, posicionar-se sobre qual seria o melhor viés para embasar uma teoria multinível dos direitos humanos. Parte-se da hipótese inicial de que a proteção aos direitos humanos atende à lógica do monismo moderado na tradição brasileira. A metodologia científica será pautada em análise doutrinária, com o objetivo final de investigar se a proteção multinível de direitos humanos melhor se adequa à teoria monista ou à teoria dualista do direito.

\section{A COEXISTÊNCIA DE MÚLTIPLAS FONTES DE PROTEÇÃO DOS DIREITOS HUMANOS}

Sem menosprezo dos documentos internacionais anteriores, a Declaração Universal dos Direitos Humanos (DUDH) de 1948, é o principal marco da proteção dos direitos humanos da era moderna. Não por acaso Norberto Bobbio aponta a DUDH como "a única prova através da qual um sistema de valores pode ser considerado humanamente fundado e, portanto, reconhecido: e essa prova é o consenso geral acerca da sua validade" (BOBBIO, 1992, p. 26). A importância da DUDH se revela no plano nacional quando os Estados internalizam os princípios do documento internacional em suas constituições, reforçando no plano interno, ainda que formalmente, 
a proteção dos direitos humanos, sobretudo na chamada terceira onda da democratização ${ }^{1}$, período em que foram promulgadas, por exemplo, a Constituição Portuguesa de 1976 e a Constituição Brasileira de 1988.

Ainda no plano internacional, a proteção dos direitos humanos se dividiu em âmbitos regionais (africano, americano e europeu) e no âmbito global. No continente africano, o sistema de proteção dos direitos humanos foi criado no seio da União Africana. A Carta Africana de Direitos Humanos e dos Povos, de 1981, e seu Protocolo Adicional de 1998 são os principais instrumentos da região para a proteção dos direitos humanos, tendo a Comissão Africana de Direitos Humanos e dos Povos e a Corte Africana de Direitos Humanos e dos Povos seus principais órgãos de proteção ${ }^{2}$ e3. A proteção dos direitos humanos no âmbito regional americano é feita por um sistema complexo (BROWNLIE, 1997, p. 599). Afinal, no continente coexistem dois mecanismos sobrepostos com pontos de partida diplomáticos diversos. 0 primeiro integra a OEA e utiliza como fontes os preceitos de sua carta criação e a Declaração Americana dos Direitos e Deveres do Homem (DADDH). O segundo tem como fonte principal a Convenção Americana de Direitos Humanos (CADH). Apesar de os "sistemas" regionais interamericanos não se excluírem, a CADH tem aplicabilidade mais restrita, haja vista que dos 35 Estados signatários da OEA o tratado é aplicável a apenas $23^{4}$.0s órgãos que compõe o SIDH são a Comissão Interamericana de Direitos Humanos ${ }^{5}$ e a Corte Interamericana de Direitos Humanos ${ }^{6}$.Na Europa encontra-se o mais completo sistema de proteção dos direitos humanos de âmbito regional. Nele coexistem o sistema da Convenção Europeia dos Direitos do Homem, que tem como órgão principal a Corte Europeia de Direitos Humanos, bem como o sistema supranacional do Tribunal de Justiça da União Europeia, que busca a proteção dos direitos humanos violados pela União Europeia e seus membros, na aplicação do direito comunitário. Há ainda a proteção dos direitos humanos feita pelo sistema universal, global ou onusiano (RAMOS, 2013, p. 77), instituído pela Resolução 1503 do Conselho Econômico e Social das Nações Unidas, também conhecido como "procedimento 1503", tendo nos Pactos de Direitos Humanos de $1966^{7}$ seus principais documentos. 
Internamente os Estados buscam a proteção dos direitos humanos por suas Constituições e normas infraconstitucionais. No Brasil, a Constituição de 1988 traz uma grande ênfase na proteção dos direitos humanos. 0 constituinte reservou capítulos inteiros para discorrer sobre o tema, como os cinco capítulos do Título I (Dos Direitos e Garantias Fundamentais) e os oito capítulos do Título VIII (Da Ordem Social), bem como o fez de forma esparsa nos demais títulos da Constituição, inserindo normas garantidoras de direitos fundamentais nos capítulos referentes à organização do Estado ou da ordem tributária. Além disso, a dignidade humana foi erigida como um fundamento da república (CF, art. 1ํㅡ, III). A prevalência dos direitos humanos consta do rol dos princípios das relações internacionais (CF, art. $4^{\circ}$, II). 0 respeito aos direitos da pessoa humana é considerado princípio constitucional sensível (CF, art. 34, VII, b), sendo seu desrespeito por um Estado-membro ou pelo Distrito Federal, hipótese de intervenção federal (CF, art. 36, III). Há ainda a vedação da deliberação de proposta de emenda à Constituição tendente a abolir direitos e garantias individuais (CF, art. 60, § 4º IV), consubstanciando uma chamada cláusula pétrea. Ademais, a Emenda Constitucional no 45, de 2004, instituiu o chamado incidente de deslocamento de competência, atribuindo à justiça federal a competência para a apuração de grave violação de direitos humanos, com o intuito de assegurar o cumprimento de obrigações decorrentes de tratados internacionais pelo Brasil (CF, art. 109, V-A c/c art. 109, § 5ㅇ).

A Constituição também traz prescrições relacionadas ao plano internacional relacionadas à integração do país para a proteção dos direitos humanos. Além da previsão do princípio de prevalência dos direitos humanos, já citada, o art. 4º, $\mathrm{X}$ da CF prevê como princípio das relações internacionais do Brasil a cooperação entre os povos para o progresso da humanidade. 0 parágrafo único do mesmo artigo prevê ao Estado brasileiro a busca da integração econômica, política, social e cultural dos povos da América Latina, visando à formação de uma comunidade latino-americana de nações. Já o art. 7o dos Atos das Disposições Constitucionais Transitórias determina ainda o ingresso do Brasil em um tribunal internacional de direitos humanos.

O Brasil, após o fim da ditadura militar, cumprindo os mandamentos constitucionais, buscou um caminho de legitimação do Estado perante a 
sociedade internacional, ratificando os principais tratados internacionais de direitos humanos, entre eles a CADH, de 1968, pelo Decreto $\cong 678 / 92$, aderindo ainda à cláusula de jurisdição obrigatória da Corte IDH em 2002, com a edição do Decreto no 4.463/02 (ainda que tenha sido fixada a adesão do país retroativa a 1998). Atualmente o país já ratificou mais de vinte tratados relacionados à proteção dos direitos humanos, considerando os sistemas global e regional de direitos humanos ${ }^{8}$. Além dos diversos atos internacionais há também normas internas, de nível constitucional e infraconstitucional, produzidas principalmente após a Constituição de 1988, reforçam a proteção desses direitos.

\section{A PROTEÇÃO MULTINÍVEL DOS DIREITOS HUMANOS POR RENÉ URUEÑA}

O autor analisa os aspectos gerais das chamadas teorias de proteção multinível dos direitos humanos, apontando suas virtudes e eventuais riscos. Parte do fenômeno da "governação multinível" originária dos debates decorrentes da integração europeia ${ }^{9}$. Trata-se de um movimento contraposto ao protagonismo estatal quando do surgimento da União Europeia, em que atores internos, como regiões e províncias, atuavam na integração com outros níveis de governo, sem a intermediação do Estadonação (URUEÑA, 2013, p. 302), expedindo normas sobre o mesmo tema. A ampla admissão dessas ideias acarretou na ampliação dessa lógica a outros processos onde coexistem normas de diferentes âmbitos, em uma mesma área, sendo os direitos humanos um desses casos (URUEÑA, 2014, p. 17).

O autor descreve o Sistema Europeu de Proteção de Direitos Humanos em quatro níveis: subnacional, nacional, supranacional e internacional. Os níveis nacional e subnacional são introduzidos pelas normas internas dos Estados, sendo a proteção feita pelos respectivos poderes judiciários. 0 nível supranacional foi introduzido pelo sistema de direitos fundamentais previstos na Carta dos Direitos Fundamentais e tutela pelo Tribunal de Justiça Europeu. Já o nível internacional foi criado pela Convenção Europeia de Direitos Humanos de 1950, que tem como órgão de tutela a Corte Europeia de Direitos Humanos (URUEÑA, 2013, p. 304). Já na América 
Latina, o autor afirma que a proteção dos direitos humanos é feita em âmbito internacional, pelo Sistema Interamericano de Direitos Humanos, e a proteção interna, por cada um dos Estados, de modo a não se afastar da lógica de proteção multinível. Contudo, no ambiente interamericano não há uma proteção em âmbito supranacional (URUEÑA, 2013, p. 309).

Após descrever o cenário fático da proteção nos dois continentes, 0 autor analisou as teorias de proteção multinível sob dois prismas: interno ou nacional e internacional. No âmbito interno questionou-se: como é feita a integração do Direito Internacional no plano nacional? (URUEÑA, 2014, p. 24). Já do ponto de vista internacional, o autor buscou debater o problema: como os sistemas jurídicos latino-americanos podem contribuir para a justiça internacional? (URUEÑA, 2014, p. 31).

No prisma internacional, a adoção de uma posição clássica internacionalista, a discussão sobre a integração do direito internacional no ordenamento interno seria, de certa forma, irrelevante, tendo em vista ser considerado um mero fato pelos tribunais internacionais ${ }^{10}$. No entanto, René Urueña (2014, p. 32) ressalta que, na prática, principalmente na jurisdição relacionada à proteção dos direitos humanos, há um diálogo entre os tribunais internacionais e os tribunais nacionais. 0 autor traça então dois modelos dessa interação em âmbito internacional: o constitucionalismo global e o pluralismo.

Para os defensores do primeiro paradigma, há um núcleo duro na ordem jurídica internacional, que serve como limite do poder, assim como o fazem as constituições nacionais. A adoção do modelo constitucionalista trás, segundo o autor, a grande vantagem de abertura às vítimas, da jurisdição internacional, para fazer cumprir a "Carta Interamericana de Direitos", permitindo a tutela dos direitos humanos quando as autoridades nacionais são abusivas ou negligentes, e os tribunais pátrios fracos ou corruptos (URUEÑA, 2014, p. 35). Contudo, esse modelo traz dois importantes riscos no contexto latino-americano. 0 primeiro é o de prometer mais que pode cumprir, tendo em vista que o acesso aos tribunais internacionais se dá mediante o princípio da subsidiariedade $^{11}$. 0 segundo risco é o de que as próprias instituições do sistema interamericano acabam por se tornarem fontes de violação dos direitos humanos. Para René Urueña (2014, p. 37), nessas situações, os 
tribunais nacionais não poderiam proteger os direitos humanos contra os abusos da organização internacional.

Já para o paradigma do pluralismo, não há supremacia entre as ordens internas e a ordem internacional. Havendo diversos sistemas jurídicos sempre aplicáveis a um mesmo problema, a questão não será resolvida por uma questão hierárquica entre ordens distintas ou de predileção de interpretações nos tribunais (internos ou internacional) (URUEÑA, 2013b, p. 371). 0 diálogo permitiria a adoção de melhores decisões e contribuiria para a criação de uma identidade da comunidade interamericana (URUEÑA, 2014, p. 38). 0 maior risco do pluralismo é a ausência de segurança jurídica por levar à promessa de proteção que seja comprometida pela aceitação de uma pluralidade legítima entre os Estados (URUEÑA, 2014, p. 40).

\section{O DUALISMO CLÁSSICO DE TRIEPEL}

Karl Heinrich Triepel, na construção de sua teoria dualista ${ }^{12}$, parte do pressuposto de que o direito internacional e o direito interno são sistemas jurídicos distintos, tendo em vista dois critérios: as relações sociais; e a vontade da qual as normas são emanadas, ou sejas, das fontes jurídicas. Em razão das relações sociais, é possível distinguir os ramos do Direito, já em função das fontes jurídicas, seria possível distinguir sistemas jurídicos (TRIEPEL, 1966, p. 8).

Para o autor o direito interno regula apenas as relações sociais das pessoas sujeitas à soberania de um Estado, em razão delas estarem em seu território. Já o direito internacional rege relações entre Estados soberanos, e somente entre Estados soberanos, que no plano internacional são "perfeitamente iguais"(TRIEPEL, 1966, p. 11). Assim sendo, para o autor, o indivíduo, no plano internacional, não está investido de direitos ou deveres, sendo apenas objeto de direitos e deveres internacionais (TRIEPEL, 1966, p. 12).

0 termo utilizado pelo autor para ilustrar a união das vontades estatais é "Vereinbarung", que é utilizado pela doutrina alemã para designar as verdadeiras uniões de vontade, distinguindo-as dos contratos, que, por 
serem sinalagmáticos, normalmente, traduzem declarações de conteúdos opostos (TRIEPEL, 1966, p. 16).

Considerando tais premissas Karl Heinrich Triepel conclui que direito internacional e direito interno são sistemas jurídicos distintos, ilustrados como "círculos em íntimo contato, mas que jamais se sobrepõem" (TRIEPEL, 1966, p. 16). O conteúdo das normas de direito internacional poderá ser convertido por uma regra de direito interno, mas isso não quer dizer que haverá uma reprodução da norma, tendo em vista que, para o autor, a natureza das obrigações é também distinta (TRIEPEL, 1966, p. 17).0s exemplos trazidos pelo autor são os de que enquanto um tratado obriga o Estado a extraditar criminosos, a lei interna autoriza as autoridades remeter o agente ao estrangeiro. Da mesma forma, um tratado obriga o Estado a conceder uma garantia a um empréstimo, enquanto a lei interna autoriza o governo a fornecê-la.

Em suma, para Karl Heinrich Triepel um tratado de direito internacional não é jamais, um meio de criação de direito interno, sendo necessária a ação da fonte material interna para substituir ou fazer executar, uma disposição prevista no tratado internacional (TRIEPEL, 1966, p. 18). Em termos de validade, para o autor, um tratado só é valido internacionalmente, isto é, só é obrigatório perante Estados e não aos seus súditos. $\mathrm{O}$ efeito prático dessa teoria é a impossibilidade de conflito entre uma norma de direito internacional e uma norma do direito interno, afinal, o âmbito de aplicabilidade de ambas é distinto.

\section{O DUALISMO/PLURALISMO INSTITUCIONALISTA DE SANTI ROMANO}

Santi Romano em sua obra “O ordenamento jurídico", de 1949, também denominada como pluralista institucionalista ${ }^{13}$, parte da negação do Direito como uma regra de conduta. Para ele o direito pode também se apresentar como norma, mas ele detém outros elementos essenciais que são, muitas vezes, relegados pela doutrina (ROMANO, 2008, p. 62). Assim como o direito não corresponde apenas a uma norma, quanto entendido de forma mais ampla, ou seja, como ordenamento jurídico, não 
pode ser também entendido como um conjunto ou sistema de normas (ROMANO, 2008, p. 66).

Afinal, se está correta a ideia de que o ordenamento jurídico é um "todo vivo" ou um "organismo" (ROMANO, 2008, p. 68) que detém força própria de expansão e adaptação, essa unidade não pode ser reduzida a um conjunto de normas sendo negligenciada a unidade em que elas foram constituídas. $\quad 0$ direito abarca, segundo o autor, não apenas o conjunto de normas, mas ainda a "entidade" que as edita. Por isso, Santi Romano entende como elementos essenciais do direito a ideia de sociedade, pois decorre de relações sociais; de ordem social, visto que as normas surgem de uma ordem social que as precede; e de integração da norma com a organização que a criou, constituindo-se uma unidade. Portanto um conceito que abarcaria tanto o direito ${ }^{14}$, enquanto o ordenamento jurídico, como uma unidade éo de instituição. Todo ordenamento jurídico é uma instituição e, vice-versa, toda instituição é um ordenamento jurídico. Existe entre os dois conceitos uma equação necessária e absoluta. (ROMANO, 2008, p. 78).

Baseando-se nos ensinamentos de Maurice Hauriou, Santi Romano (2008, p. 81) compreende a instituição como uma coletividade despersonalizada, semelhante ao que o direito alemão denomina Einrichtng. Para ele há duas espécies de instituições: a primeira referese a coisas inertes (como um terreno, considerado por si mesmo, no registro de imóveis) e a segunda formada por corpos sociais, e, por isso, também denominadas instituições corporativas.

As instituições coorporativas são entidades fechadas que diferem dos indivíduos que fazem parte, podendo possuir, ou serem candidatas a possuir personificação própria (ROMANO, 2008, p. 81). As instituições podem ser consideradas em função de suas relações com o mundo exterior, ou em suas relações internas.

Portanto, para Santi Romano para cada instituição existente há um ordenamento jurídico equivalente. Note-se que o autor aponta que a noção de licitude não é requisito existencial de uma instituição. Uma instituição é "todo enteou corpo social" (ROMANO, 2008, p. 81). Assim sendo, organizações criminosas, desde que instituídas e estruturadas internamente, com normas próprias de modo a ser individualizada, é 
considerada uma instituição e, por isso, detém um ordenamento jurídico próprio, ainda que ele não seja reconhecido pelo Estado ${ }^{15}$.

Para o autor a sociedade internacional tambémé uma instituição, sendo dela decorrente um ordenamento jurídico próprio, o direito internacional:

[...] o direito internacional é o ordenamento imanente da comunidade dos Estados; que nasce com ela, sendo dela inseparável; que é necessário procurá-lo na instituição em que se concretiza tal comunidade, mais do que em normas advindas de acordos particulares; e que este é, portanto, antes de tudo e no seu aspecto unitário, organização ou instituição. (ROMANO, 2008, p. 104).

Considerando a multiplicidade de ordenamentos jurídicos, Santi Romano (2008, p. 163) classifica as instituições considerando parâmetros, como a fonte de sua criação, seus fins, o âmbito de eficácia, personificação, dependência ${ }^{16}$. Ademais ele destaca a relevância na relação entre as instituições, isto é, que o conteúdo ou eficácia de um ordenamento seja condicionada ao de outro (ROMANO, 2008, p. 167).

No que diz respeito ao ordenamento internacional e aos ordenamentos estatais nacionais, para Santi Romano as relações entre esses ordenamentos são regidas pela vontade superior da comunidade internacional e pela independência dos Estados. (ROMANO, 2008, p. 144). Entende que ainda que o ordenamento internacional seja superior ao dos Estados, os ordenamentos nacionais não dependem dele no que concerne a sua existência ou à validade de suas manifestações individuais. A autonomia do Estado não é um atributo advindo do Direito Internacional, em função de seu caráter originário, ao contrário do que ocorre em um Estado federal que é parcialmente originário (ROMANO, 2008, p. 174).

Contudo, apesar de admitir antinomia entre as normas dos ordenamentos internos e internacional, o autor refuta a ideia de um Estado que não seja organizado ou constituído assegurando a conformidade da conduta às regras da sociedade internacional (ROMANO, 2008, p. 180). Porém, no plano da validade, um Estado que contraria as disposições do DIP viola internacionalmente um dever relevante, mas seu ordenamento interno continua legítimo. Isso ocorre pela independência dos ordenamentos nacionais em relação ao internacional. Admite a possibilidade de influência 
do ordenamento internacional sobre o conteúdo do ordenamento estatal, mas isso não ocorre por uma questão de direito de uma ordem sobre a outra, mas sim pelo cumprimento de um dever do Estado perante os outros Estados. Nesse sentido o autor afirma que "é sempre o Estado que determina o conteúdo do próprio ordenamento" (ROMANO, 2008, p. 182).

A teoria de Santi Romano assemelhando-se a Triepel baseia-se na afirmação de que os destinatários das normas internacionais são apenas os Estados e não seus órgãos ou indivíduos. Retira-se, portanto, da esfera jurídica dos indivíduos a obrigação de zelo pelo Direito Internacional dos Direitos Humanos. Se um indivíduo comete um crime de guerra, não deve apenas o Estado ser responsabilizado.

\section{O MONISMO NACIONALISTA: A UNIDADE DO ORDENAMENTO JURÍDICO E A PRIMAZIA DO ESTADO SOBERANO}

Para os partidários do monismo, "o mundo jurídico é forçosamente unitário” (DINH, DAILLIER e PELLET, 2003, p. 96).

Parte das doutrinas monistas nacionalistas buscam inspiração na noção hegeliana de Estado, personificação do máximo ético ${ }^{17}$, dotado de soberania interna e externa. A soberania interna como vontade una do Estado personalizado ${ }^{18}$ que prepondera aos particulares (HEGEL, 1997, p. 255) e soberania externa como indivíduo dotado de independência dos demais Estados (HEGEL, 1997, p. 295). Já o Direito Internacional, é para Hegel o "resultado entre Estados independentes" (HEGEL, 1997, p. 301). As normas do DIP seriam, então, resultado da vontade dos Estados fundamentada na "autonomia da vontade", e não em uma vontade geral $^{19}$. Considerando esses dois pressupostos, conclui-se que apesar de uno o sistema jurídico, as normas nacionais preponderam sobre as normas internacionais.

No Brasil, três posicionamentos distintos relacionados ao status normativo dos tratados internacionais são doutrinariamente considerados: constitucional; supralegal; e legal. 
As cláusulas constitucionais referentes ao status dos tratados internacionais de direitos humanos (ressaltem-se: art. 1ํㅡ, III, art. 4ํㅡ, I e art. $5^{\circ}$, $§ 2^{\circ}$ da Constituição brasileira), pressupõem que os tratados internacionais, não ratificados nos termos do art. 5ํㅗ § $3^{\circ}$ da Constituição, teriam força de normas supralegais, paralisando a eficácia da legislação ordinária, no que lhe for contrária, mas respeitando a supremacia da Constituição. Por sua vez, aqueles aprovados nos termos deste último normativo adquirem status constitucional.

O maior problema da teoria monista nacionalista é o de, na prática, ser ela equivalente às teorias dualistas, pois nessas duas posições o que prevalece é o Direito interno. 0 monismo nacionalista ainda se mostra falho pelo seguinte paradoxo: ou ele tem pretensão de colocar um determinado Estado (que o adota) no centro do mundo, afirmando que na unidade de todo o Direito (interno e nacionais) são as normas desse estado o ápice da experiência jurídica; ou se equipara a uma teoria dualista/pluralista, ao reconhecer o mesmo direito de sobreposição a todos os ordenamentos nacionais, negando, assim, o direito internacional e a própria unidade do Direito. Por tais motivos, conclui-se que a doutrina monista nacionalista não é adequada para a defesa dos direitos humanos, pois se mostra mais preocupada com status de poder de seus órgãos, a soberania ilimitada do Estado, do que com os seres humanos a serem protegidos.

\section{MONISMO INTERNACIONALISTA: A PRIMAZIA DO DIREITO INTERNACIONAL}

Resta agora analisar a corrente monista internacionalista. Vários autores defendem essa posição, sob pontos de vista distintos. Hersch Lauterpacht defende um monismo naturalista compreendendo o DIP com a função primordial de cuidar do bem-estar dos indivíduos, sendo sua primazia essencial para melhor garantir esse objetivo (SHAW, 2010, p. 103). DINH, DAILLIER e PELLET (2003, p. 94) citam também o monismo internacionalista elaborado por George Scelle, fundamentado por elementos sociológicos ${ }^{20}$. Para o autor, todas as sociedades têm funções sociais essenciais (criação do Direito, Jurisdição e execução), 
inclusive a sociedade internacional, ainda que de forma imperfeita. 0 Direito Internacional seria como o direito interno, aplicável aos indivíduos, inexistindo um direito apenas entre Estados. Logo, a pretensa soberania seria da sociedade (de indivíduos) internacional e não aos Estados (DINH, DAILLIER e PELLET 2003, p. 81). Não obstante tais posições, a defesa de maior proeminência do plano internacional é a de Hans Kelsen. Para Kelsen, Direito Internacional só pode ser considerado Direito se corresponder à fórmula "uma ordem coercitiva da conduta humana ${ }^{21}$, pressuposta como soberana" (1999, p. 224).

Contudo, apesar da conceituação do autor, ele não coaduna com a ideia de que apenas os Estados são sujeitos do DIP (KELSEN, 2000, p. 486). Ao contrário de Triepel e Santi Romano, Kelsen aponta que o direito é uma regulamentação da conduta humana. Nesse sentido, sendo o direito internacional direito, o conteúdo de suas normas cria direitos e obrigações tanto a pessoas jurídicas, como os Estados, quanto aos indivíduos. Mais que isso, o autor destaca que quando o DIP regulamenta a conduta do Estado ele regulamenta, na verdade, a conduta dos indivíduos que o representam, adotando, portanto, a teoria do órgão (KELSEN, 2000, p. 487).

O conteúdo das normas do DIP são, para Kelsen (2000, p. 489), majoritariamente incompletas, isto é, compostas apenas de seu elemento material (comando do que deve ser feito), mas não de seu elemento pessoal (quem deve fazer ou não a conduta). Desse modo caberia aos Estados complementar a norma em âmbito interno, fornecendo o elemento pessoal. Porém, isso não quer dizer que não haja normas completas no DIP. 0 melhor exemplo trazido pelo autor é a proibição da pirataria ${ }^{22}$, que não é destinada a Estados, mas a indivíduos, ainda que na legislação nacional não haja norma correspondente.

Outro ponto importante da teoria de Kelsen (KELSEN, 2000, p. 497) é a distinção entre normas necessariamente de Direito Internacional e normas pertencentes ao Direito Internacional. Nas primeiras caberia apenas ao DIP a regulamentação, não admitindo regulamentação pelo Direito nacional. Nas segundas a natureza da norma seria de direito internacional (como aquisição e perda da nacionalidade) mas sua regulamentação é feita pelo direito nacional ${ }^{23}$. 
Porém, como os Estados são independentes, eles não podem impor a outros a aplicação de sua ordem jurídica (KELSEN, 2000, p. 498), cabendo assim ao DIP, através do princípio da efetividade, delimitar a validade das ordens jurídicas nacionais. Para o ele o Direito Internacional regula sua própria criação, que nem sempre decorre do princípio da pacta sunt servanda. Nesse ponto Kelsen faz uma construção interessante. Há fontes do DIP que são oponíveis a terceiros que não participaram, propriamente de sua criação. 0 principal exemplo do autor seriam os costumes internacionais. Afinal, um costume é oponível a Estados que não participaram de sua criação (KELSEN, 2000, p. 500). Até mesmo tratados internacionais podem gerar efeitos a terceiros, como os de criação de um Estado (tal como no Tratado de Versalhes e o Tratado de Latrão).

0 autor critica ainda a visão dualista (de Triepel) sob o ponto de vista lógico. Não seria possível a coexistência de normas mutuamente independentes, pertencentes a sistemas distintos, válidas em um mesmo espaço e ao mesmo tempo (KELSEN, 2000, p. 516). A gênese dessa ideia seria a de que o DIP cuida de "negócios externos" do Estado, enquanto o direito nacional de "negócios internos". 0 autor não nega a correlação entre direito internacional, como direito interestatal, contrapondo-se ao direito nacional entendido como direito uniestatal. A questão é que enquanto o DIP tem de suas normas criadas com a participação de mais de um Estado, para Kelsen (2000, p. 519) não há matéria que esteja excluída a possibilidade de ser regulada pelo DIP. Em outros termos, para o autor, todas as matérias do Direito nacional são ou podem ser regulamentadas pelo DIP.

A escolha sobre a prevalência da norma interna ou internacional, para Kelsen, deve ser feita pela Constituição de cada Estado (KELSEN, 2000, p. 539). Caberá, portanto, ao Direito positivo, sendo o motivo dessa escolha situado fora do Direito, isto é, na ética, filosofia ou decorrente de uma ideologia política. Um Estado influenciado por ideias nacionalistas e imperialistas tenderia a dar primazia ao Direito nacional, já outro de lado pacifista e simpático ao internacionalismo, daria ênfase à primazia do Direito Internacional (KELSEN, 2000, p. 551). 


\section{MONISMO MODERADO E O MONISMO DIALÓGICO: UMA SAÍDA AOS CONFLITOS FORMAIS E A PREPONDERÂNCIA DA NORMA MAIS FAVORÁVEL AO SER HUMANO}

As correntes monistas até então debatidas são denominadas por Jorge Miranda (2012, p. 136) de radicais, contrapondo-se a uma linha mais mitigada, ou moderada ${ }^{24}$ em que a relação entre o Direito Internacional e o Direito interno não resultarão necessariamente, em uma relação de validade, podendo acarretar uma simples ineficácia ou a responsabilidade do Estado.

Outro ponto aventado por Jorge Miranda para a adoção do monismo moderado seria o de que o monismo internacionalista radical pressupõe algo parecido como um federalismo mundial (utópico atualmente). Para o autor o primado do Direito Internacional deve ser variado em função dos diversos setores do cada vez mais complexo DIP atual (MIRANDA, 2012, p. 137):

A relação do Direito Internacional comum com o direito interno tende a ser, um pouco por toda a parte, uniforme e constante; e o primado do primeiro - mormente, do jus cogens - traduz, afinal, o primado do bem comum universal. Em contrapartida, a relação do Direito Internacional convencional e do Direito das organizações internacionais e de entidades afins com o Direito interno tem-se revelado bastante diversificada - diversificada por causa do conteúdo e dos objetivos das próprias normas internacionais e diversificada por causa das legítimas opções constitucionais dos vários Estados. (MIRANDA, 2012, p. 138)

Considerando que a norma de proteção internacional dos direitos humanos, que, por sua natureza, integram, em sua grande maioria, o rol das chamadas normas de jus cogens ${ }^{25 e} 26$,são imperativas ${ }^{27}$ e inderrogáveis ${ }^{28}$, e, portanto, têm validade própria, não podendo os Estados se afastar de seu cumprimento, sendo considerados nulos tratados que disponham em sentido contrário. Logo, adotada a teoria monista internacionalista não haveria possibilidade de descumprimento de suas normas pelo Estado.

Por outro lado, Antônio Augusto Cançado Trindade (2007, p.435) ${ }^{29}$ ressalta que em relação às normas do DIDH acabam por mitigar a 
discussão sobre a prevalência de normas internas e internacionais. Isso ocorre porque, através das chamadas cláusulas de comunicabilidade ou abertura (MALISKA, 2013, p. 117), presentes na maioria das Constituições Latino-americanas e também nos tratados internacionais de direitos humanos, deverá prevalecer o ordenamento que contenha a norma mais favorável à vítima.

Em relação SIDH, o art. 29 da CADH traz a previsão expressa de que as normas da convenção não poderão ser interpretadas para suprimir o gozo ou exercício de direitos reconhecidos em seu texto ou em virtude de leis ou outros tratados assinados por um dos Estados-partes. Já o art. 5ㅜㅡ, $\S 2^{\circ}$ da Constituição brasileira trás previsão semelhante, ressaltando que os direitos previstos na Constituição não excluíram outros, decorrentes dos princípios constitucionais ou tratados internacionais ratificados pelo Estado brasileiro.

No mesmo sentido, mas por fundamentos distintos, Valerio Mazzuoli (2016, p. 112) defende uma posição monista dialógica. Em princípio caberiam às normas do Direito Internacional prevalecerem sobre a ordem interna. Contudo, considerando a teoria do diálogo das fontes de Erik Jayme e a possibilidade formal prevista nos tratados de direitos humanos, num caso concreto, em função do princípio pro homine, seria possível a norma nacional prevalecer, exatamente por melhor proteger o ser humano (MAZZUOLI, 2010, epub).

Inicialmente ressalta-se que as chamadas cláusulas de abertura, ao contrário do que prediz Cançado Trindade, não mitigam a discussão monistas/dualistas, pois segundo as teses dualistas, tanto de Santi Romano quanto de Triepel, não há de se falar em conflito de normas ou de jurisdição. Os autores refutam até mesmo a chamada tese do "reenvio" do ordenamento interno ao um tratado internacional, em virtude do destinatário da norma de cada um dos ordenamentos. Assim sendo, a noção de conflito normativo é ínsita às correntes monistas, que, preveem apenas uma ordem jurídica, com regras de múltiplos níveis.

Contudo, a conclusão do autor está correta, haja vista que, aplicando a norma nacional ou a norma internacional, o resultado do "conflito" não será a preponderância formal de um ordenamento sobre o outro, mas sim teleológico, de aplicação da norma mais favorecida ao ser humano. 
Portanto, o ponto de prevalência de normas, essencial à defesa dos direitos humanos se insere em uma teoria monista, prevalecendo não um nível sobre o outro, mas sim o chamado princípio pro homine.

\section{CONCLUSÃO}

Considerando o que até então foi dito, a conclusão de René Urueña sobre a possibilidade de divisão de teorias de proteção multinível de vieses monistas e dualistas, se mostra ainda mais difícil, principalmente seja do ponto de vista lógico, seja por uma questão de prática jurídica.

A noção dualista de Triepel, apesar de sua importância histórica, hoje não se sustenta. Afinal, apesar de a contenda sobre o indivíduo ser ou não sujeito de DIP remontar à época de Francisco de Vitória ${ }^{30}$, atualmente a maioria da doutrina concorda sobre sua posição como sujeito de Direito Internacional ${ }^{31}$.

A pessoa natural é dotada de direitos e deveres no plano internacional. Em relação aos direitos, a própria existência dos direitos humanos, assim como também ado direito humanitário, revelam-se como os principais marcos a favor dos indivíduos ${ }^{32} .0$ artigo 6o do Estatuto de Roma, por sua vez, estabelece três categorias distintas de crimes internacionais, que ensejam a responsabilidade internacional da pessoa natural ${ }^{33}$ : crimes contra a paz, de guerra e contra a humanidade. Ademais, a pessoa natural tem legitimidade ativa e tem legitimidade passiva internacional. Os tribunais ad hoc de Nuremberg, Ruanda e da Ex-Iugoslávia e o Tribunal Penal Internacional são exemplos claros da legitimidade passiva internacional do indivíduo. Já a legitimidade ativa é presente preponderantemente nos sistemas de proteção internacional dos direitos humanos, principalmente no sistema europeu, em que o indivíduo tem acesso direto ao Tribunal Europeu de Direitos Humanos.

0 principal problema da teoria de Triepel é o não reconhecimento de obrigações jurídicas internas surgidas de tratados internacionais, que, por sua vez, deságua na ausência do conflito entre normas internas e internacionais. Os "ciclos íntimos" descritos pelo autor seriam, na verdade, duas retas paralelas, que não se tocam jamais. Esse problema é 
compartilhado pela teoria de Santi Romano, ao impedir que os indivíduos sejam destinatários das normas do Direito Internacional Público.

Portanto, considerar o paradigma pluralista mencionado por René Urueña, não apenas dá protagonismo aos tribunais nacionais, como também não lhe retira a posição de poder relacionada à última palavra sobre a aplicação do direito no Estado, independentemente da decisão de um tribunal internacional. Ademais, a lógica de aplicabilidade de direito comparado, sem princípios com validade jurídica que determinam a preponderância de uma norma sobre a outra, apenas fortalece o papel os órgãos internos, fazendo com que o descumprimento de uma decisão internacional seja reduzida a um ilícito internacional do Estado, inoponível pelo indivíduo em âmbito interno (tal qual defendem Triepel e Santi Romano). 0 problema desse paradigma ultrapassa a mera aceitação de respostas distintas pelas vítimas, ou a ausência de segurança jurídica, mas sim a possibilidade de um verdadeiro non liquet em âmbito internacional ao ser utilizado desmedidamente instrumentos como a "margem de apreciação" ou pelo descumprimento reiterado das decisões internacionais pelos órgãos internos.

A teoria de Kelsen, por sua vez, se mostra a melhor aplicável à defesa dos direitos humanos que as posições dualistas. Afinal, o autor admite a aplicabilidade de normas internacionais oponíveis a indivíduos no plano interno, bem como permite a oposição de tratados internacionais por indivíduos contra os Estados. Contudo, há alguns pontos da teoria que merecem certa ponderação. 0 primeiro refere-se à suposta pureza do Direito, restrito ao Direito positivo e afastados de elementos morais. A história já demonstrou que a devoção cega ao Direito, independente de seu conteúdo, tende a gerar mais injustiças do que justiça. Por essa teoria o Direito positivo poderia ser alterado, esvaziando a defesa dos Direitos Humanos e ainda ser um direito aplicável.

Outro ponto a ser ressaltado é que a correspondência entre Direito e Estado. Se do ponto de vista nacional essa correspondência é absoluta, na teoria elevada ao plano internacional o autor admite a possibilidade de uma norma ser aplicada a um Estado que não participou de sua formação. Contudo, mesmo nessa hipótese, a norma, para Kelsen não deixou de ser formulada por um Estado. Transpondo essa lógica aos dias atuais, há 
fontes do Direito, como a jurisprudência internacional que é aplicável aos Estados e, apesar de não haver sido por ele produzida. Por fim, ressalte-se na atualidade, a possibilidade de normas como as contidas no Artigo $27^{34}$ da Convenção de Viena sobre o Direito dos Tratados (CVDT), de $1969^{35}$, as quais retratam a interferência direta entre as jurisdições internacional e nacionais.

Portanto, conclui-se que a proteção multinível dos direitos humanos só é possível sob as bases de uma teoria monista, diante de um conflito de normas que deverá ser solucionado por elas pertencerem a um mesmo sistema jurídico. Dos três grandes grupos de teorias monistas, a que melhor possibilita tal proteção é o monismo dialógico ou moderado, pois tem como critério jurídico de solução dos conflitos normativos o princípio pro homine. De certo que a adoção desse modelo importa que os tribunais, nacionais e internacionais, fundamentem suas decisões de modo a justificar em cada caso concreto a preponderância de uma norma nacional em razão de uma norma internacional, e vice-versa ${ }^{36}$. Isso impediria qualquer a possibilidade de alegações da teoria da quarta instância, ou contrariedade ao princípio da subsidiariedade.

\section{NOTAS}

1 Samuel Huntington, em sua clássica obra "A terceira onda" (The third wave) conceitua como onda de democratização como "um grupo de transições de regimes não democráticos para democráticos que ocorre em um determinado período de tempo superando significativamente o número de transições em sentido oposto" (HUNTINGON, 1991, p. 15) (tradução nossa). Segundo o autor, a primeira onda ocorreu no período entre 1828 a 1926, a segunda entre 1943 a 1962 e a terceira a partir de 1974.

2 Cf. BRANT, PEREIRA e BARROS (2007, p. 6917).

3 Em 2003 a União Africana terminou o protocolo adicional do Tribunal de Justiça da União Africana, que teria a finalidade ser o principal órgão jurisdicional da União Africana (artigo $2^{\circ}$ ), tendo a competência de interpretação de qualquer instrumento adotado no quadro da União e qualquer questão do direito internacional (artigo 19). 0 tribunal nunca chegou a ser criado, pois o protocolo não conseguiu o número mínimo de ratificações.

4 Ao todo 25 Estados ratificaram a Convenção, porém Trinidad e Tobago (em 1998) e a Venezuela (em 2012) a denunciaram.

5 A CIDH é um órgão criado em 1959, pela Resolução VIII, na V Reunião de Consulta dos Ministros das Relações Exteriores. Apenas em 1965, por meio da Resolução XXII, da II Conferência Interamericana do Rio de Janeiro, de 1965, ela passou a ter competência para receber petições ou comunicações de direitos humanos. 0 órgão tem sede em Washington e é composto por 7 membros, que deverão ser pessoas de alta autoridade moral e de reconhecido saber em matéria de direitos humanos (CADH, art. 34).A CIDH é um órgão principal da OEA, mas autônomo (RCIDH, art. 1.1). 
6 A Corte IDH não é órgão da OEA, mas sim da Convenção Americana de Direitos Humanos. Tem sede em San José, na Costa Rica. Ela é composta por 7 juízes (CADH, art. 52) , escolhidos pelos Estados-partes da Convenção, em sessão da Assembleia Geral da OEA de uma lista de candidatos propostos pelos próprios Estados (CADH, art. 53).

7 O Pacto Internacional sobre os Direitos Civis e Políticos e o Pacto Internacional sobre os Direitos Econômicos, Sociais e Culturais, ambos de 1966

8 Segundo dados do Senado Federal, atualizados no ano de 2013, têm-se o seguinte cenário: atos não ratificados, mas aprovados pelo Brasil: Declaração Universal dos Direitos Humanos; Declaração Americana dos Direitos e Deveres do Homem; Declaração sobre o Direito ao Desenvolvimento; Declaração e Programa de Ação de Viena; Declaração de Pequim Adotada pela Quarta Conferência Mundial sobre as Mulheres: Ação para Igualdade, Desenvolvimento e Paz; Estatuto da Corte Interamericana de Direitos Humanos; Declaração das Nações Unidas sobre os Direitos dos Povos Indígenas. Tratados ratificados pelo Brasil: Convenção sobre a Escravatura; Convenção para a Prevenção e a Repressão do Crime de Genocídio; Convenção sobre os Trabalhadores Migrantes: Convenção 97; Convenção Relativa ao Estatuto dos Refugiados; Convenção sobre Asilo Territorial; Convenção Suplementar sobre a Abolição da Escravatura, do Tráfico de Escravos e das Instituições e Práticas Análogas à Escravatura; Convenção Internacional sobre a Eliminação de Todas as Formas de Discriminação Racial; Pacto Internacional sobre Direitos Civis e Políticos; Pacto Internacional sobre Direitos Econômicos, Sociais e Culturais; Convenção Americana de Direitos Humanos: Pacto de São José da Costa Rica; Protocolo sobre o Estatuto dos Refugiados; Convenção sobre a Eliminação de Todas as Formas de Discriminação contra a Mulher; Convenção contra a Tortura e Outros Tratamentos ou Penas Cruéis, Desumanos ou; Degradantes; Convenção Interamericana para Prevenir e Punir a Tortura; Protocolo Adicional à Convenção Americana sobre Direitos Humanos em Matéria de Direitos Econômicos, Sociais e Culturais: Protocolo de São Salvador; Convenção sobre os Direitos da Criança; Protocolo Adicional à Convenção Americana sobre Direitos Humanos Referente à Abolição da Pena de Morte; Convenção Relativa à Proteção das Crianças e à Cooperação em Matéria de Adoção; Internacional; Convenção Interamericana para Prevenir, Punir e Erradicar a Violência contra a Mulher: Convenção de Belém do Pará; Convenção Interamericana sobre Tráfico Internacional de Menores; Estatuto de Roma do Tribunal Penal Internacional; Convenção Interamericana para a Eliminação de Todas as Formas de Discriminação contra as Pessoas Portadoras de Deficiência; Protocolo Facultativo à Convenção sobre a Eliminação de Todas as Formas de Discriminação contra a Mulher; Protocolo Facultativo à Convenção sobre os Direitos da Criança Referente à Venda de; Criança, à Prostituição Infantil e à Pornografia Infantil; Protocolo Facultativo à Convenção sobre os Direitos da Criança Relativo ao Envolvimento de Crianças em Conflitos Armados; Protocolo Facultativo à Convenção contra a Tortura e Outros Tratamentos ou Penas Cruéis, Desumanos ou Degradantes; Convenção das Nações Unidas contra a Corrupção: Convenção de Mérida; Convenção sobre a Proteção e Promoção da Diversidade das Expressões Culturais; Convenção sobre os Direitos das Pessoas com Deficiência e seu Protocolo Facultativo.

9 O autor cita como base o artigo “European Integration from the 1980s: State-Centric v. Multi-level Governance" de Gary Marks, Liesbet Hooghe e Kermit Blank, onde são traçados os contornos de uma "governança multinível" como um movimento de contraposição à governança estatal-centralizada ou intergovernamental, quando da integração europeia.

10 Tal posição está positivada no Artigo 27 da Convenção de Viena sobre o Direito dos Tratados, de 1969: "Artigo 27 Direito Interno e Observância de Tratados Uma parte não pode invocar as disposições de seu direito interno para justificar o inadimplemento de um tratado. Esta regra não prejudica o artigo 46".

11 Portanto, não se retira a competência primária dos Estados para a proteção das pessoas sujeitas à sua jurisdição. Mas nas hipóteses de falha ou proteção aquém à necessária, o sistema interamericano passa a atuar, suprindo o Estado omisso.

12 Provavelmente a teoria dualista mais importante e conhecida.

13 Cf. VIEIRA. 2015, p. 111. 
14 Para Santi Romano o vocábulo direito tem duas acepções: a primeira refere-se ao ordenamento em sua unidade, ou seja, uma instituição; a segunda a um preceito ou conjunto de preceitos sistematizados ligados a um ordenamento jurídico (ROMANO, 2008, p. 78).

15 Uma família, por ter normas internas a serem observadas por seus membros, e por poder ser considerada uma individualidade, é considerada uma instituição e, por isso, também detém seu ordenamento jurídico. (ROMANO, 2008, p. 90).

16 Quanto à fonte de criação do ordenamento: Instituições originárias: em que suas normas não são colocadas por outras instituições, e, portanto, detém uma fonte de produção independente; Instituições derivadas: cujo ordenamento é posto por outra instituição. Nesse caso há uma relação de superioridade entre o ordenamento originário e o derivado. Instituições parcialmente originárias: o ordenamento dessas instituições pode assumir um caráter específico de independência, ainda que parcialmente. Quanto aos fins: Instituições com fins particulares: concernente a alguns aspectos da vida humana, como o econômico ou religioso. São, por sua natureza, limitadas à circunscrição de seus fins; Instituições com fins gerais: abordam aspectos de sua estrutura e de relações com outros entes, sendo fundamentadas sobre uma extensa sujeição aos seus membros. Em outros termos, tem fins ilimitados ou, pelo menos alteráveis por seus membros. Quanto à sua eficácia: Estritamente interna: quando as normas valem apenas em seu âmbito constitutivo; Eficácia ampla: quando o ordenamento é aplicável a entes externos aos componentes da instituição. Um exemplo seria a aplicabilidade do ordenamento estatal aos estrangeiros. Quanto à sua composição: Instituições simples: composta por apenas um ente; Instituições complexas: com postas por mais de uma instituição menor. Nessa hipótese, em regra, a instituição maior tem uma relação de subordinação com as instituições menores. Quanto à dependência: Instituições perfeitas: são sempre originárias, e independem de outras instituições; Instituições imperfeitas: são, de regra, derivadas, mas dependem de outras instituições em relações de coordenação ou subordinação. Quanto à personificação: Instituições personificadas: detentoras de personalidade jurídica própria. Detém poder próprio que subordina seus membros. Instituições despersonificadas: não detém esse poder, podendo seus membros serem iguais ou se fundamentar pela supremacia de um membro sobre os demais. Quanto às suas relações: Instituições reciprocamente independentes: detentoras de relações baseadas na igualdade entre elas. Instituições dependentes: que podem deter relações coordenadas (também baseadas na igualdade dos membros) ou subordinadas.

17 Nos dizeres de Hegel "[...] o elemento fundamental da personalidade abstrata no direito imediato, que se desenvolveu através das diferentes formas da subjetividade e agora, no direito absoluto, no Estado que é a objetividade plenamente concreta da vontade, surge como personalidade do Estado, a sua certeza de si. E a instância suprema que suprime na sua unidade todas as particulares que interrompe a perplexidade se fim entre e as causas e objetos, que conclui pelo eu quero, iniciando toda a ação e toda realidade" (HEGEL, 1997, p. 255).

18 O Estado hegeliano se faz presente no plano real através do monarca (HEGEL, 1997, p. 256).

19 "O fundamento do direito dos povos como direito universal que entre os Estado é válido em si e para si e que é diferente do conteúdo particular dos contratos reside no dever de se respeitar os contratos, pois neles se fundam as obrigações dos Estados uns para com os outros. Como, porém, a relação entre eles tem por princípio a sua soberania, daí resulta que se encontram uns perante os outros num estado de natureza e os seus direitos não consistem numa vontade universal constituída num poder que lhes é superior mas obtêm a realidade das suas recíprocas relações na sua vontade particular" (HEGEL, 1997, p. 303).

20 Cf. SHAW, 2010, p. 103.

21 Para o autor uma regra de Direito trata-se de um julgamento hipotético como um ato coercitivo, ou seja, uma sanção, imposta pela prática de um delito.

220 autor também dá os exemplos de quebra de bloqueio e contrabando de guerra, em que a sanção ao indivíduo seria o confisco da carga (KELSEN, 2000, p. 490).

23 Para saber quais são essas normas necessariamente de Direito Internacional, o autor faz referência aos elementos constitutivos do Estado. A ordem normativa nacional é possível através da validade normativa a uma parcela da população mundial, presente em um determinado território.

24 Cf. ACCIOLY, SILVA e CASELLA, p. 213. 
25 As normas de jus cogens podem ser conceituadas como o conjunto de normas que incorporam os valores "supremos" (CASSESE, 2013, p. 215), "essenciais" (RAMOS, 2013, p. 47) ou "fundamentais" (BRONWLIE, 1997, p. 536; SHAW, 2010, p. 98.) da sociedade internacional, sendo consideradas ainda como "super-normas" (FOCARELLI, 2008, p. 430), tendo em vista sua posição hierárquica frente às demais normas do Direito Internacional. Estão previstas nos artigos 59 e 64 da Convenção de Viena sobre o Direito dos Tratados (CVDT), de 1969 e nos artigos 53 e 64 da Convenção de Viena sobre Direito dos Tratados entre Estados e Organizações Internacionais (CVDTEOI), de 1986 (ainda não ratificada pelo Brasil).

26 Na doutrina pode ser citado como exemplos MIRANDA, 2012 e p. 123 e BIANCHI, 2008, p. 495. A Corte Interamericana de Direitos Humanos, por sua vez, declarou a primeira vez uma norma de direitos humanos como de jus cogens em 1993 no Caso Aloeboetoe e outros vs. Surinam, tendo em sua jurisprudência vastos julgados declarando normas do DIDH como de jus cogens. Em 1998, o Tribunal Penal Internacional ad hoc para a ex-Iugoslávia, no Caso Furundžija, manifestou-se também em relação do status de jus cogens da proibição à tortura. A Corte Europeia de Direitos Humanos, por sua vez, se manifestou-se a primeira vez sobre a proibição da tortura como norma de jus cogens em 2001 no Caso Al-Adsani vs. Reino Unido. Já a Corte Internacional de Justiça se manifestou em 2012 no Caso Questões relativas à obrigação de processar ou extraditar (Bélgica v. Senegal).

27 A imperatividade das normas de jus cogens decorre de uma base objetiva (PEREIRA e QUADROS, 2001, p. 281). A própria expressão jus cogens tem por fim afastar-se de um jus dispositivm. As normas de jus cogens têm força jurídica própria, com os inerentes efeitos na subsistência de normas e atos contrários (MIRANDA, 2012, p. 117).

28 Por inderrogabilidade entende-se a impossibilidade dos Estados, por meio de acordo, afastar o conteúdo de uma norma de jus cogens (SHAW, 2010, p. 99 e BROWLIE 1997, p. 537). Valério Mazzuoli (2008, p. 133) ressalta que desde o direito romano existiam normas que não poderiam ser alterada pela liberalidade das partes: jus publicum privatorum pactis mutari non potest (D. 2.14.38). 0 autor explica que o termo jus publicum equivale ao atual direito cogente, sendo a gênese das chamadas normas de ordem pública.

29 No presente domínio da proteção, não mais há pretensão de primazia do direito internacional ou do direito interno, como ocorria na polêmica clássica superada entre monistas e dualistas. No presente contexto, a primazia é da norma mais favorável às vítimas, que melhor as proteja, seja ela norma de direito internacional ou de direito interno. Este e aquele aqui interagem em benefício dos seres protegidos. É a solução expressamente consagrada em diversos tratados de direitos humanos, da maior relevância por suas implicações práticas. (CANÇADO TRINDADE, 2007, p.435)

30 Cf. ACCIOLY, 2009, p. 49

31 Em sentido contrário: RESEK, 2010, p. 154.

32 Como bem apontam DINH, DAILLIER e PELLET (2003, p. 665) é na qualidade de pessoas naturais, seja individualmente ou em conjunto como um todo, que a algumas normas é atribuída força especial de inderrogáveis (como as normas de jus cogens). Cf. MAZZUOLI, 2017, p. 217.

34 Vide nota 14.

35 Ratificada no Brasil pelo decreto no 7.030/09.

36 Um exemplo da aplicação do princípio pro homine pela Corte Interamericana de Direitos Humanos relacionado ao Brasil foi no Caso Trabalhadores da Fazenda Brasil Verde Vs. Brasil. Isso porque à época dos fatos vigia internamente a redação original do art. 149 do Código Penal, que foi posteriormente alterado pela Lei $n \underline{0} 10.803 / 03$, trazendo uma redação mais ampla que os tratados de direito internacional analisados pelo tribunal. A consequência foi que o Brasil não foi condenado a alterar a legislação interna, ainda que tenha sido responsabilizado por violações de direitos humanos, considerando a legislação vigente à época. 


\section{REFERÊNCIAS}

ACCIOLY, Hildebrando, SILVA, G. E. do Nascimento e CASELLA, Paulo Borba. Manual de direito internacional público. 17ạ ed. São Paulo: Saraiva, 2009.

BOBBIO, Norberto. A era dos direitos. Rio de Janeiro: Campus, 1992.

BRANT, Leonardo Nemer Caldeira, PEREIRA, Luciana Diniz Durães; e BARROS, Mariana Andrade e. Sistema Africano de Proteção dos Direitos Humanos. in: XVI Anal do Congresso Nacional do CONPEDI, 2007, Belo Horizonte. Sistema Africano de Proteção dos Direitos Humanos, 2007.

BROWLIE, Ian. Princípios de Direito Internacional Público. Lisboa: Fundação Calouste Gulbenkian, 1997.

CASSESE, Antonio. Diritto Interanazionale. 2ª ed. Milano: 1 Mulino, 2013.

CANÇADO TRINDADE, Antônio Augusto. Tratado de direito internacional dos direitos humanos. vol. 1, 1aㅡ ed. Porto Alegre: 2007, Sergio Antônio Fabris Editor.

COMPARATO, Fábio Konder. A afirmação histórica dos direitos humanos. $8^{a}$ ed. São Paulo: Saraiva, 2013.

DINH, NguyenQuoc, DAILLIER, Patrick e PELLET, Alain. Direito internacional público: Formação do direito, sujeitos, relações diplomáticas e consulares, responsabilidade, resolução de conflitos, manutenção da paz, espaços internacionais, relações econômicas, ambiente. $2^{\underline{a}}$ ed. Lisboa: Fundação Calouste Gulbenkian, 2003.

FOCARELLI, Carlo. Promotional Jus Cogens: A Critical Appraisal of Jus Cogens' Legal Effects. in: Nordic Journal of Internacional Law 77. Leiden: 2008.

KELSEN, Hans. Teoria Pura do Direito. 4.ed. São Paulo: Martins Fontes, 2000.

HEGEL, Georg Wilhelm Friedrich. Princípios da filosofia do direito. São Paulo: Martins Fontes, 1997.

HUNTINGON, Samuel. Democracy's third wave. In: Journal of Democracy, spring, 1991. 
MAZZUOLI, Valerio de Oliveira. 0 controle jurisdicional da convencionalidade das leis. 3a . ed. rev. atual. e ampl. São Paulo: Editora Revista dos Tribunais, 2013.

MAZZUOLI, Valerio de Oliveira. Curso de direito internacional publico. 10. ed. rev. Atual. e ampl. São Paulo: Editora Revista dos Tribunais, 2016.

MENDES, Gilmar Ferreira. A supralegalidade dos Tratados internacionais de Direitos Humanos e a prisão civil do depositário infiel no Brasil. in: Controle de convencionalidade: um panorama latino-americano: Brasil, Argentina, Chile, México, Peru, Uruguai. Coord.: MARINONI, Luiz Guilherme e MAZZUOLI, Valerio de Oliveira. Brasília, DF, Gazeta Jurídica, 2013.

MIRANDA, Jorge. Curso de Direito Internacional Público. 5. ed. rev. e atual. Parede: Princípia Editora, 2012.

MALISKA, Marcos Augusto, Comentário ao art. 5ํㅗ § $2^{\mathbf{0}}$ da Constituição.in: CANOTILHO, J. J. Gomes, SARLET, Ingo Wolfgang, STRECK, Lenio Luiz e MENDES, Gilmar Ferreira. (Coords.) Comentários à Constituição do Brasil. São Paulo: Saraiva/Almedina, 2013.

SHAW, Malcolm N. Direito Internacional. São Paulo: Martins Martins Fontes, 2010.

RAMOS, André de Carvalho. Processo Internacional de Direitos Humanos. 3. ed. São Paulo: Saraiva, 2013.

RESEK, Francisco. Direito internacional público: curso elementar. 12 ed. rev. e atual. São Paulo: 2010.

ROMANO, O Ordenamento Jurídico. Florianópolis: Fundação Boiteux, 2008.

URUENA, Rene. Luchas Locales, Cortes Internacionales: Una Exploración De La Protección Multinivel De Los Derechos Humanos En América Latina. in: Revista Derecho del Estado, no. 30, 2013. Disponível em: <https://ssrn.com/ abstract $=2307762>$. Acesso em: 3 de setembro de 2017.

URUENA, Rene. Constitucionalismo sin Constitución, pluralismo sin pluralidad. Una réplica a Paola Andrea Acosta Alvarado, in: Revista Derecho del Estado, no $31,2013$. 
URUENA, Rene. Proteção multinível dos direitos humanos na América Latina? In: GALINDO, George Rodrigo Bandeira, URUEÑA, René e PÉREZ, Aida Torres. Proteção Multinível dos Direitos Humanos, 2014.

TRIEPEL, Karl Heinrich. As relações entre o direito interno e o direito internacional. in: Revista da Faculdade de Direito. Universidade Federal de Minas Gerais, no 6, 1966

VIEIRA. Reginaldo de Souza. Pluralismo Jurídico Clássico: A contribuição de Ehrlich, Santi Romano e Gurvitch. in: Direito, Estado e Sociedade, no 47. Rio de Janeiro, 2015.

Recebido em: 26-11-2018

Aprovado em: 16-11-2020

\section{Paula Regina Arruda de Azevedo}

Pós-doutura pela Universidade de Duisburg-Essen-Alemanha. . Doutora em Direitos Humanos pela Universidade de Salamanca - Espanha. Mestre em Instituiçoes Jurídico-políticas pela Universidade Federal do Pará (2004). Graduação em Direito pela Universidade da Amazônia (2001). Professora na Universidade Federal do Pará, com ênfase em Direito Constitucional e Direitos Humanos.

E-mail: paularruda_pa@yahoo.com.br

\section{Paulo Máximo de Castro Cabacinha}

Doutorando pela Universidade Federal de Minas Gerais (ingresso em 2021). Mestre em Direito pela Universidade Federal do Pará (2019). Especialista em Direito Internacional (2006) e Estudos Diplomáticos (2008) pelo CEDIN/Milton Campos. Graduado em Direito pela Pontifícia Universidade Católica de Minas Gerais (2005). Juiz Federal lotado na $3^{\underline{a}}$ Relatoria da 1a Turma Recursal das Seções Judiciárias do Pará e Amapá, vinculado ao Tribunal Regional Federal da 1ํㅡㄹ Região. Professor de Direito Constitucional na graduação e pós-graduação na Faculdade Estácio em Belém/PA.

E-mail: paul0maximo@uol.com.br

\section{Universidade Federal do Pará}

R. Augusto Corrêa, 01 - Guamá, Belém - PA, CEP: 66075-110 
